\title{
The Effect of Rubber Band Resistance Exercise on Blood Glucose Level of Patient With Type 2 Diabetes Mellitus
}

\author{
Ni Luh Putu Inca Buntari Agustini \\ Bachelor of Nursing Department, Institute of Health \\ Sciences Bali \\ Bali, Indonesia \\ inca.stikesbali@gmail.com
}

\author{
I Gusti Ayu Puja Astuti Dewi \\ Bachelor of Nursing Department, Institute of Health \\ Sciences Bali \\ Bali, Indonesia
}

\begin{abstract}
Introduction: There is compelling evidence that type 2 diabetes mellitus (T2DM) is more likely to develop in individuals who are insufficiently active. Resistance exercise (RE) has received high recognition as a cornerstone in the management of T2DM. There are several advanced research about RE. However, those do not use rubber band during exercise. Therefore, the purpose of this study was to examine the effect of rubber band resistance exercise on blood glucose level of the patient with T2DM. Methods: The research design was one group pretestposttest design (rubber band resistance exercise) as the treatment given to the patient with T2DM. Fifteen participants were randomly selected from PHC 2 South Denpasar, Bali, in March 2017. Each participant was given exercise using the rubber band in groups carried out every day with a duration of $\mathbf{3 0}$ minutes for a week. Blood glucose level was measured by using blood glucose test before and after the intervention. Results: The result showed rubber band resistance exercise was statistically significant decrease the level of blood sugar by $25.43 \mathrm{mg} / \mathrm{dl}$, (p $<0.05$ ). Discussion/Conclusion: Resistance exercise using the rubber band is an alternative form of exercise for the T2DM patient. There is good evidence that rubber band resistance exercises improving glycemic control patients with T2DM.
\end{abstract}

Keywords: rubber band resistance exercise, blood glucose level, type 2 diabetes mellitus

\section{INTRODUCTION}

The global epidemic of obesity has contributed to a tendency of growing incidence the prevalence of Type 2 Diabetes Mellitus (T2DM). The World Health Organization forecast that the number of people with T2DM will double from 347 million in 2008 to about 550 million worldwide by the year 2030, largely because of dietary and other lifestyle factors [1]. Therefore, the disease is a growing public health concern and alarmingly dangerous condition, especially to health care systems. T2DM (90-95\% of cases) results from a combination of the inability of muscle cells to respond to insulin properly (insulin resistance) and inadequate compensatory insulin secretion [2], [3].

Disturbances in glucose and insulin metabolism may not be a normal characteristic of aging but rather associated with dietary habits, and physical inactivity [4]. Physical
Activity (PA) is an important part of diabetes management for the prevention of progression towards complications (Horden et al. 2012). Furthermore, PA has received increasing recognition as a cornerstone in the prevention and treatment of T2DM. PA in the form of regular exercise can improve blood glucose control, maintain or lose weight, prevent obesity, normalize blood pressure and improve insulin action (Strasser \& Pesta, 2013). Participant in PA on a regular basis is linked to the prevention of illness and improvement in health status. High-quality studies on PA as the management of DM showed that regularity exercises significant influence on the successful management of type 2 diabetes by $40 \%$, and lowering blood glucose level of $30.14 \mathrm{mg} / \mathrm{dl}$. This proves that by doing regular PA can improve glycemic control among patients with T2DM [5], [6].

Although PA is a key element in the prevention and management of T2DM, many people with this chronic disease do not become or remain regularly active, most people with Type 2DM are not active. Many barriers encountered in physical activity, such as time, place and the tools used. All of these conditions cause a possible failure to exercise regularly. Evidence from several randomized controlled trials (RCT) showed the difficult to access the modern equipment, the need to travel to a fitness center, the cost of a fitness service membership, and the cost and space requirements of home equipment contribute to poor regularly exercise [7].

Recently, PA with resistance band has become popular. In this study, the boarder term "physical activity" (defined "bodily movement produced by the contraction of skeletal muscle that substantially increases energy expenditure) is used interchangeably with "resistance exercise, by using the rubber band. The rubber band is made of strong, thin rubber with handles at the end, and come in a variety of resistance. Interestingly, there are ten benefits of using Rubber Band during exercise such as 1) incredibly cost effectiveness, 2) adaptable for people with T2DM, 3) can often use with familiar strength training, 4) can be used for a comprehensive, fullbody workout hat challenges virtually every major muscle group in the body, 5) save on storage space, 6) excellent for using during travelling, 7) add variety, 8) easy to use alone, 9) can be combined with other equipment, and 10) also extremely effective at working the muscles [8] 
People with T2DM require close supervision in physical activity. The criteria that must be met people with T2DM is FIT (frequency, intensity, and time) so that the patient is completely scalable in activity. There are several advanced research about physical activityhowever; the studies do not use rubber band during exercise. Furthermore, the effect of resistance exercise on blood glucose level in people with T2DM has not been reported. Therefore, the purpose of this study was to examine the effect of rubber band resistance exercise on blood glucose level of the patient with type 2 diabetes mellitus. We hypothesized that resistance exercise using rubber band would result in significant impact to manage blood sugar level.

\section{METHODS}

The research design was one group pretest-posttest design (rubber band resistance exercise) as the treatment given to the patient with T2DM. The population of this study was patients with T2DM in PHC 2 South Denpasar, sub-district, Bali-

study. Participant were randomized selected and meet the inclusion criteria such as 1) T2DM patients who were willing to participate in resistance exercise by using rubber band for 30 minutes every day for a week, 2) blood sugar level as <400 $\mathrm{mg} / \mathrm{dl}$ were measured before treatment, 3) during exercise the pulse reaches target heart rate (THR). There are seven people who drop out in this study because five people are not willing to continue treatment and two people could not reach THR up to 30 minutes of exercise. So that, the sample size in this study was fifteen patient with T2DM.

Data was collected in March 2017 by using questionnaire and observation in blood sugar level (as the variable in this research); as well as the observation THR. A self-developed questionnaire was used for data collection to determine the personal data and information about the treatment carried out previously. Observation is used to record the measurement of blood sugar level before the intervention (pre-test) and blood sugar level after the intervention (post-test). Materials and equipment used consisted of a needle, adjustable lancing devices, alcohol 70\%, cotton, Glico Dr strip, blood glucose test meter, tape recorder, and watches. Measuring instrument used in this study is a measure that is standard blood glucose test and Glico Strip as the reagent. The blood is taken from the peripheral blood to the fingertips. Blood sampling performed by a designated officer that two people who have been trained enumerators/training that results or data obtained are not biased. Respondents were given a questionnaire to be filled in, accompanied by researchers. Examination of blood sugar level is done one day before the intervention and subsequently recorded on the observation sheet.

Approval and permission to conduct the study obtained from the Board for National Unity and Peoples' Protection of Bali Province (070/00371/DPMPTSP-B/2017). Also, permission to conduct the study was obtained from the head of PHC 2 South Denpasar, sub-district, Bali. Participants have signed the inform consent forms indicating their permission and willingness to participate in the study. Researchers kept anonymity and confidentiality of participants' identity and responsibility. The result findings were presented in aggregate.
The normality of the variable was evaluated using ShapiroWilk statistics with $\mathrm{p}>.05$. Descriptive statistics were then calculated. The general characteristics are presented as frequencies and percentages, with average, and standard deviation also provided. The paired samples t-test was used for analysis of change independent variables before and after exercise. All differences with $\mathrm{p}<.05$ were accepted as statistically significant [9].

\section{RESULTS}

\section{Table 1. General characteristics of the respondents $(n=15)$}

\begin{tabular}{|l|l|}
\hline Variable & Mean (SD) \\
\hline Age (years) & $63.13(7.42)$ \\
Gender (male/female) & $6 / 9$ \\
BMI (kg/m2) & $22.67(4.65)$ \\
Blood glucose (mg/dl) & \\
Pre & $201(100.15)$ \\
Post & $176.47(88.19)$ \\
Blood pressure (mmHg) & \\
Pre (Systole/Diastole) & $134.67(15.06)$ \\
Post & $127.33(11.63)$ \\
(Systole/Diastole) & $77.13(6.55)$ \\
Heart rate (bpm) & $78.93(7.37)$ \\
Pre & \\
Post & \\
\hline
\end{tabular}

Shown in Table 1, the average of age is 63 years old. In term of BMI, the average of participants was in normal BMI (22.67), with BMI ranges was $18.5-24.9 \mathrm{~kg} / \mathrm{m}^{2}$. Blood glucose level was changed $25.43 \mathrm{mg} / \mathrm{dl}$, blood pressure was changed $7.34 \mathrm{mmHg}$, and the heart rate increased $1.80 \mathrm{bpm}$.

Table 2. Paired-samples t-test analysis of the effect of rubber band resistance exercise on blood glucose level of patient with T2DM $(n=15)$

\begin{tabular}{|c|c|c|c|c|c|}
\hline \multirow[t]{2}{*}{$\begin{array}{l}\text { Intervent } \\
\text { ion }\end{array}$} & \multicolumn{2}{|c|}{$\begin{array}{l}\text { Blood glucose } \\
\text { level }\end{array}$} & \multirow[t]{2}{*}{$\mathrm{t}$} & \multirow[t]{2}{*}{$f^{d}$} & \multirow[t]{2}{*}{$\mathrm{p}$} \\
\hline & $\begin{array}{c}\text { Pre } \\
\text { (Mean } \\
+ \text { SD) }\end{array}$ & $\begin{array}{lr}\begin{array}{r}\text { Post } \\
(\mathrm{Me}\end{array} \\
\text { an } \\
\text { SD) }\end{array}$ & & & \\
\hline $\begin{array}{l}\quad \text { Rubber } \\
\text { band } \\
\text { resistance } \\
\text { exercise }\end{array}$ & $15^{201}+100$. & $\begin{aligned} & 176 . \\
& 47 \\
&+88.19\end{aligned}$ & $.07^{2}$ & $4^{1}$ & 000 \\
\hline
\end{tabular}

Shown in table 2, there was statistically significant decrease the level of blood sugar within group before exercise $(\mathrm{M}=201$, $\mathrm{SD}=100.15)$ and after exercise $(\mathrm{M}=176.47, \mathrm{SD}=88.19), \mathrm{t}$ $(14)=2.02, p<0.05$ (two-tailed). The mean decrease in blood sugar level was 25.43 . The eta squared statistics (.28) indicated a large effect size.

\section{DISCUSSION}

One of the goal treatment in T2DM is to achieve and maintain blood glucose level. Diet and exercise are the key 
elements to the management and prevention of T2DM. Many people with T2DM can achieve blood glucose control by following a nutritious meal plan and exercise. Several factors influence exercise fuel use, but the most important are the intensity and duration of exercise [10]. The current study showed that rubber band resistance exercise was significantly by reducing blood glucose level in the patient with T2DM. The participants were done the exercise using rubber band 30 minute/days for a week (210 hours) respectively, and blood glucose level was decreased $25.43 \mathrm{mg} / \mathrm{dl}$. During the data collection, the participants stated that they only ever used rubber for doing everything daily, but never used it for exercise. So that, they were very interested in doing exercise.

With increasing exercise intensity, there is a greater reliance on carbohydrates as long as sufficient amounts are available in muscle or blood. Early in exercise, glycogen provides the bulk of the fuel for working muscles. As glycogen stores become depleted, muscles increase their uptake and use of circulating blood glucose, along with free fatty acids released from adipose tissue. Intramuscular lipid stores are more readily used during longer-duration activities and recovery. Glucose production also shifts from hepatic glycogenolysis to enhance gluconeogenesis as duration increases [11], [12].

The evidence stated that during the moderate intensity of resistance exercise in $\mathrm{T} 2 \mathrm{DM}$, blood glucose level tends to decrease. It was related to the continuous, rhythmical, interval, progressive and endurance of the exercise [13]. Rubber band resistance exercise is the exercise that uses a rubber. The rubber band is made of strong, thin rubber with handles at the end, and come in the variety of resistance. A rubber band can use in various ways as exercise can be performed in all directions. Considering that exercise using rubber band, are incredibly cost effectiveness, adaptable for people with T2DM, can often use with familiar strength training, can be used for a comprehensive, full-body workout hat challenges virtually every major muscle group in the body, save on storage space, excellent for using during travelling, add variety, easy to use alone, can be combined with other equipment, and also extremely effective at working the muscles (Mercola, 2013). For most people with T2DM, exercise is recommended for diabetes management and can be undertaken safely and effectively [7].

\section{CONCLUSION}

Resistance exercise is well-established prevention strategy, treatment, and management therapy for patients with T2DM. This research results revealed that the rubber band resistance exercise was significantly affected by reducing blood glucose level in the patient with T2DM. Therefore, by the results obtained, the rubber band resistance exercise has potential benefit to reduced blood glucose level of the patient with T2DM. However, more studies are essential to evaluate the effectiveness with more rigor studies. It also expects, resistance exercise should be an essential component of any treatment plan for all patients with T2DM.

\section{REFERENCES}

$$
\text { B. Strasser and D. Pesta, "Resistance Training for }
$$

Diabetes Prevention and Therapy: Experimental Findings and Molecular Mechanisms," vol. 2013, 2013.

[2] J. . Black, J.M., \& Hawks, Medical surgical nursing, 8th ed. singapore: Elsevier Inc, 2010.

[3] L. . and K. A. W. Leontis, "Symptoms develop gradually with type 2 diabetes. Diabetes Symptoms," 2010. .

[4] M. D. Hordern, D. W. Dunstan, J. B. Prins, M. K. Baker, M. A. F. Singh, and J. S. Coombes, "Exercise prescription for patients with type 2 diabetes and prediabetes: A position statement from Exercise and Sport Science Australia," Journal of Science and Medicine in Sport, vol. 15, no. 1. pp. 25-31, 2012.

[5] S. K. McGinley, M. J. Armstrong, N. G. Boulé, and R. J. Sigal, "Effects of exercise training using resistance bands on glycaemic control and strength in type 2 diabetes mellitus: a meta-analysis of randomised controlled trials," Acta Diabetologica, vol. 52, no. 2. pp. 221-230, 2014.

[6] E. Mårdberg, "Effect of Resistance Training in Patients with Type 2 Diabetes Mellitus:- A Systematic Review.” 2014.

[7] C. Care, E. H. Morrato, J. O. Hill, H. R. Wyatt, V. Ghushchyan, and P. W. Sullivan, "Physical activity in U.S. adults with diabetes and at risk for developing diabetes, 2003," Diabetes Care, vol. 30, no. 2, pp. 203-209, 2007.

[8] Mercola, "10 benefits of using resistance band during exercise.," 2013.

[9] J. Pallant, SPSS survival manual: A step by step guide to data analysis using SPSS. 2010.

[10] et al Bajpeyi S, Tanner CJ, Slentz CA, "Effect of exercise intensity and volume on persistence of insulin sensitivity during training cessation," J Appl Physiol, 2009.

[11] H. Boon, E. E. Blaak, W. H. M. Saris, H. A. Keizer, A. J. M. Wagenmakers, and L. J. C. Van Loon, "Substrate source utilisation in long-term diagnosed type 2 diabetes patients at rest, and during exercise and subsequent recovery," Diabetologia, vol. 50, no. 1, pp. 103-112, 2007.

[12] Y. Wang, D. Simar, and M. a Fiatarone Singh, "Adaptations to exercise training within skeletal muscle in adults with type 2 diabetes or impaired glucose tolerance: a systematic review," Diabetes Metab Res Rev, vol. 25, pp. 13-40, 2009.

[13] L. E. Black, P. D. Swan, and B. A. Alvar, "Effects of intensity and volume on insulin sensitivity during acute bouts of resistance training," J. Strength Cond. Res., vol. 24, no. 4, pp. 1109-1116, 2010. 